\title{
INCORPORATING SOCIAL MEDIA IN RESEARCH AND ACADEMICS
}

\author{
Dr.S.Mercy Gnana Gandhi \\ Dept of English, Sathyabama University \\ drmerci2010@gmail.com
}

\begin{abstract}
:
The evolution of internet technology and subsequent increase in the use of online social networking applications have been undeniably considered as a milestone in the web history. Recent advances in web science allow users to create websites, manage their identities and stay connected with others, providing comprehensive digital traces of social actions, interactions and transactions. With its profound impact on our daily lives, social media has become the most important conduit for brands to build loyalty, empowering the consumers with a wealth of information at finger tips. No doubt, online social networks have revolutionized the practice of interaction among the researchers, who demand new methods and tools for collecting, processing and mining the data. Being a bundle of techniques and technologies, these networks are really an extensive attempt to promote the researchers to render the ideas of communication, collaboration and collection. Such networking resources help us in developing collaboration among different organizations, universities around the world by exploring the benefits of research activities and also by extending the promotion of academics. Organizations find it an advantage for reaching a large pool of potential consumers with less time and effort. Now, with the effective display of online web based tools, collaborative working ambience is the need of the hour, for any academic institution, for enhancing the productivity and for promoting the results. However, this type of socializing has raised concerns about the privacy and security of internet users. The present paper briefly discusses the task of social media in research and academics, the various networking resources and tools and also their impacts on researchers and students.
\end{abstract}

Keywords: Internet Technology, Social networks, Social media, researchers, academics, online

\section{INTRODUCTION:}

With the advent of the internet and technology information, the world has become closer and the interaction among the community has become limitless through social media like newspapers, telephone, emails, SMS services, scraps, blogs or through social networking sites. Particularly, researchers, academicians and scientists completely rely on social networks to gear up their professional profile, to express their ideas and to transfer information. This paper is definitely an attempt to familiarize the researchers, scientists and scholars about the latest online networking tools and resources , focusing on the three main ideas of communication, collaboration and collection through social networks. Such networks can change the way by which a research is undertaken and has come up new forms of communication in a efficient way.

\section{Social Media- A culture?}

Social media is an internet service in which the online contents are generated by the service consumers. It draws together a variety of social networking tools with different functionality and unique culture. Building up a healthy network takes time and the process of building, creating and filtering useful networks is absolutely a skill, which needs to have much practice. The proper utilization of social media and the development of phenomenol networking is a mixed blessing for the researchers and academicians of this age. The service providers of these networks have unique policies for the consumer generated content and numerous procedures for data collection, sharing and publication. For instance, Face book is used exclusively for social purposes whereas Linkedln has been used mainly for professional networking.

\section{SOCIAL NETWORKING TOOLS}

\section{A. Communication networking tools}

Blogging (Blogger, TypePad, WordPress LiveJournal), Microblogging (Twitter, Google Buzz ,Yammer),Location (Facebook Places,Foursquare, Gowalla) Social networking(Linkedln, MySpace, Facebook) Aggregators ( Pageflakes, iGoogle, Google Reader, Netvibes) are few of the Communication networking tools. 


\section{B. Collaboration networking tools}

Conferencing(GoToMeeting, Skype, Adobe Connect), Wikis (Wetpaint, PBworks, Wikia), Social bookmarking(Diigo, Delicious, BibSonomy),Social bibliography (CiteULike, Mendeley, Zotero), Social news (Newsvine, Digg, Reddit), Social documents (Dropbox, Google Docs, Zoho), Project management( Huddle, Bamboo, Basecamp)

\section{Multimedia networking tools}

Photographs (SmugMug, Flickr, Picasa), Video ( YouTube, Viddler, Vimeo) Live streaming ( Livestream, Justin.tv , Ustream) Presentation sharing (SlideShare, Sliderocket, Scribd) Virtual worlds Second Life, World of Warcraft, OpenSim)

\section{SOCIAL NETWORKING PLATFORMS FOR RESEARCHERS}

ResearchGate is a wonderful social networking site designed intentionally for the researchers and scientists to share their papers, short reviews and research interests. It provides academic score based on citation index and also offers private chat rooms for scientists to share and edit their professional data on confidential topics. Being a huge database of professionals, Linked in encourages the potential employers and job seekers.

A network platform for academicians created to read articles, to distribute research ideas and to upload them is academia.edu. It is very much helpful in connecting with different scientist of the world and in improving collaboration. It is very quick in getting the feedback immediately. The Graduate Junction, is a networking resource for early stage researchers, doing their masters or Ph.D. It is a very good discussion forum, indexing by category of our research, a database of conferences around the world together. Method Space is also a social networking service for scientists aims at bring together researchers from different disciplines. A free Web-based service from Google, is Google doc. Drop box, is a Webbased file hosting service to enable the users to store and share files and folders with others across the Internet..

\section{SOCIAL BOOKMARKING SERVICES}

Delicious is one of the most popular social bookmarking services. A combined view of everyone's bookmarks with a given tag is available; for instance, the
URL http://delicious.com/tag/wiki displays all of the most recent links tagged "wiki". Its collective nature makes it possible to view bookmarks added by other users. Diigo is a social bookmarking website which allows signed-up users to bookmark and tag web-pages. Additionally, it allows users to highlight any part of a webpage and attach sticky notes to specific highlights or to a whole page. BibSonomy is an academically-orientated service with many of the features of delicious plus the metadata gathering capabilities of a social citation service. This is useful since it allows all resources - from informal Web sources to formal published resources - to be stored and accessed in a single location.

\section{SOCIAL CITATION TOOLS}

CiteULike enables you to store, tag and retrieve bibliographic information. CiteUlike emphasizes the social elements of citation sharing and encourages you to make 'connections' with other researchers and to 'watch' what other people are adding to their library. Mendeley describes itself as a reference manager and academic social network. It integrates with Word and a range of other applications. Zotero is another bibliographic service which contains some social/ collaboration elements.

\section{BLOGGING TOOLS}

Blogger is a free weblog publishing tool from Google, for sharing text, photos and video. This is probably the most user friendly blogging platform out there. You can set up as many blogs as you want and right from your Google account. Wordpress is a hosting platform that makes it easy for anyone to publish online and is different from WordPress.org.

\section{A. Microblogging tools}

Twitter is the clear market leader, a general tool used for a wide range of purposes. The discussion that you participate in will vary depending on who you are following and how you engage with them. Tumblr and Plurk which offers a stranded structure for the microblog conversations.

\section{B. What do social media mean for researchers}

Consumption of information and knowledge results in a fruitful research. A number of mechanisms have been designed to smooth the progress of the transfer of knowledge between scientists and researchers. Quality 
assurance mechanisms like appointment committees, peer review, publication and review are underpinned by a variety of social interactions and forms of collaboration. Collaboration is involved in research including researchers, librarians, funders and the public. It is true that social tools have the potential to contribute something to each of these stages. But they also have the potential to challenge the ways in which research is done.

\section{Academic use of social media}

No doubt, social media has a greater impact on education; Particularly, higher education by creating and promoting virtual learning environments for augmenting distributed learning. Learners thus formulate their virtual communities and interact freely with each other. They can exchange their learning experiences, research findings and academic opportunities. There are a variety of reasons and styles which seem justifying the use of social media including web 2.0 for academic purpose. The comprehensive report 2008, revealed that social media was exploited by learners in different ways for augmenting and supporting their learning process, promoting opportunities of reflecting \& collaborating, sharing and communicating among distributed learners but depending upon the quality and availability of technical infrastructure for having an access to use it.

\section{CONCLUSION:}

Therefore, to build a network for ourselves in Social media we have to keep our motivation going. There are few services that become successful, since they automatically recommend links based on shared interests or shared contacts. However, we probably shouldn't leave the creation of our network to a machine. It is [10] . important that we have to actively go looking for the right people to add to our network. Social media can be used not only for the promotion of research but also for research development .These platforms will allow academics to digest more content, more quickly. We have to be clear how to use social media in an academic setting.

\section{REFERENCES}

[1] Carr, Nicholas. (2010) The Shallows: What the Internet Is Doing to Our Brains. W.W. Norton, ISBN 978-0-393-072228

[2] Giles J. (2005) Internet encyclopaedias go head to head. Nature 438: 900-901.

[3] Montanari, A., Saberi, A. (2010) The spread of innovations in social networks. Proceedings of the NationalAcademy of Sciences USA. 107(47):

[4] Procter, R., Williams, R., \& Stewart, J. (2010). If you build it, will they come? How researchers perceive and use web 2.0. London: Research Information Network.

[5] Shirky, C. (2010) Cognitive Surplus: Creativity and Generosity in a Connected Age. Allen Lane. ISBN 9781594202537

[6] Gewin, V. (2010) Collaboration: Social networking seeks critical mass. Nature 468(7326): 993-994.

[7] Rajagopalan et al. (2010). Accuracy of cancer information on the Internet: A comparison of a Wiki with aprofessionally maintained database. Journal of Clinical Oncology 28:7s, 2010. Retrieved 2010-06-05).

[8] Darren W. Logan, Massimo Sandal, Paul P. Gardner, Magnus Manske, Alex Bateman. Ten Simple Rules for Editing Wikipedia. PLoS Comput Biol, Vol. 6, No. 9. (2010), e1000941.doi:

[9] Keen, Andrew. (2007) The Cult of the Amateur: How the Democratization of the Digital World isAssaulting Our Economy, Our Culture, and Our Values. Doubleday Currency, ISBN 978-0385520805 